\title{
Review \\ Developments in the scientific and clinical understanding of autoinflammatory disorders
}

Helen J Lachmann and Philip N Hawkins

National Amyloidosis Centre and Centre for Acute Phase Proteins, Department of Medicine, University College London Medical School, Hampstead Campus, Rowland Hill Street, London NW3 2PF, UK

Corresponding author: Helen J Lachmann, h.lachmann@medsch.ucl.ac.uk

Published: 30 January 2009

This article is online at http://arthritis-research.com/content/11/1/212

Arthritis Research \& Therapy 2009, 11:212 (doi:10.1186/ar2579)

(c) 2009 BioMed Central Ltd

\begin{abstract}
The autoinflammatory diseases, also known as periodic fever syndromes, are disorders of innate immunity which can be inherited or acquired and which cause recurrent, self-limiting, seemingly spontaneous episodes of systemic inflammation and fever in the absence of autoantibody production or infection. There has been much recent progress in elucidating their aetiologies and treatment. With the exception of familial Mediterranean fever, which is common in certain populations, autoinflammatory diseases are mostly rare but should not be overlooked in the differential diagnosis of recurrent fevers since DNA diagnosis and effective therapies are available for many of them.
\end{abstract}

\section{Introduction}

The autoinflammatory conditions are a group of multisystem disorders of innate immunity characterised by fluctuating or irregularly recurring episodes of fever and systemic inflammation, affecting the skin, eyes, joints, and serosal surfaces. They include the hereditary syndromes familial Mediterranean fever (FMF), tumour necrosis factor (TNF) receptor-associated periodic syndrome (TRAPS), the hyper-lgD and periodic fever syndrome (HIDS), and the cryopyrin-associated periodic syndrome (CAPS) and acquired diseases of adulthood, including urate arthropathy and Schnitzler syndrome.

Despite some similarities in symptoms, there are major distinctions in the aetiology, inheritance, duration and frequency of 'attacks', and the overall clinical picture of the various disorders (Table 1). These diseases are generally compatible with normal life expectancy, bar the significant risk of developing AA amyloidosis. Recent insights into their molecular pathogenesis with identification of susceptibility genes and characterisation of new proteins and pathways have led to improved diagnosis and development of rational therapies and have shed fascinating new light on aspects of the innate immune system.

\section{The inherited fever syndromes Familial Mediterranean fever}

This was first described in New York in 1945 by Sheppard Siegal, although the term familial Mediterranean fever was not coined until 1958 [1].

\section{Genetics and pathophysiology}

The gene associated with FMF, MEFV on chromosome 16, encodes a protein called pyrin and was identified through positional cloning in 1997 [2,3]. MEFV is constitutively expressed in neutrophils, eosinophils, monocytes, dendritic cells, and synovial fibroblasts and is upregulated in response to inflammatory activators such as interferon- $\gamma$ and TNF- $\alpha$ [4]. The more than 40 MEFV mutations associated with FMF encode either single amino acid substitutions or deletions (Infevers registry database [5]). Disease-causing mutations occur mostly in exon 10 but also occur in exons 1, 2, 3, 5, and 9. Mutations in each of the two MEFV alleles are found in $85 \%$ of patients with FMF, whilst the great majority of individuals with a single mutated allele are healthy carriers [6]. The methionine residue at position 694 may be especially important for pyrin's function; three different mutations involving M694 have been identified, and homozygosity for $\mathrm{M} 694 \mathrm{~V}$ is associated with a severe phenotype. Interestingly, simple heterozygous deletion of this residue has been associated with autosomal dominant FMF in northern

$\mathrm{CAPS}=$ cryopyrin-associated periodic syndrome; CB2BP1 $=$ CD2-binding protein- 1 CINCA = chronic infantile neurological, cutaneous, and articular syndrome; CPPD = calcium pyrophosphate dihydrate; FCAS = familial cold autoinflammatory syndrome; FMF = familial Mediterranean fever; HIDS = hyper-IgD and periodic fever syndrome; IL = interleukin; LRR = leucine-rich repeat; MSU = monosodium urate; MVA = mevalonic aciduria; $\mathrm{MVK}=$ mevalonate kinase; MWS = Muckle-Wells syndrome; NF-KB = nuclear factor-kappa-B; NOMID = neonatal onset multisystem inflammatory disease; PAMP = pathogen associated molecular patterns; PAPA = pyogenic sterile arthritis, pyoderma gangrenosum, and acne; PYD = pyrin domain; SAA = serum amyloid A protein; TNF = tumour necrosis factor; TNFR1 = tumour necrosis factor receptor $1 ; T N F R S F 1 A=$ tumour necrosis factor receptor superfamily $1 \mathrm{~A}$; TRAPS = tumour necrosis factor receptor-associated periodic syndrome. 


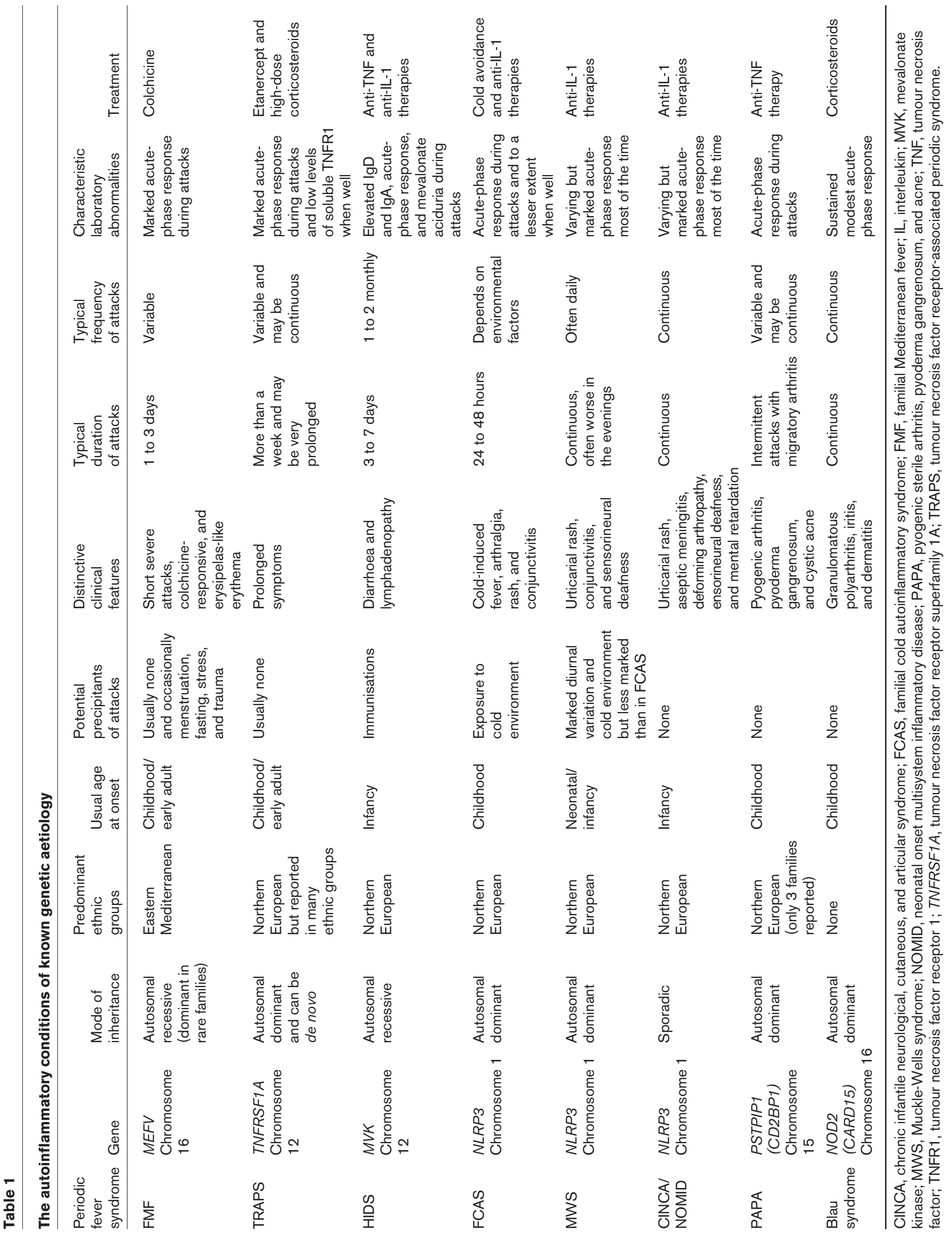


Europeans [7]. Greater disruption of a single MEFV allele by two or more mutations can also cause dominant inheritance, although FMF affecting more than one generation in typical populations usually represents pseudodominant inheritance due to consanguinity or a high prevalence of carriers.

One particular pyrin variant, E148Q encoded in exon 2, has allele frequencies of $10 \%$ to $20 \%$ in Asian populations and up to $1 \%$ to $2 \%$ in Caucasians. Whilst pyrin E1480 can cause FMF when coupled with an exon 10 mutation, homozygosity for E148Q alone is not associated with the disease in the vast majority of cases. There is some evidence that FMF carriers, perhaps especially those with pyrin $\mathrm{E} 148 \mathrm{Q}$, may have an augmented response to some types of non-FMF inflammation $[8,9]$.

Neither the structure nor the function of pyrin has yet been fully characterised, although subtle abnormalities of leukocyte function have been reported in FMF patients and upregulated MEFV expression has been identified in critically ill children with multiple organ failure [10]. The putative 781-amino acid protein has sequence homologies with a number of proteins of apparently disparate function and cellular localisation. Pyrin is thought to interact with a variety of proteins within the cytoplasm and to play a key role in the modulation of inflammation and apoptosis [11]. Many of its interactions appear to involve its 90-amino acid $\mathrm{N}$-terminal death domain, which is now classified generically as a pyrin domain (PYD) in other proteins that have homology with pyrin's N-terminal sequence [12]. Members of the death domain superfamily are involved in the assembly and activation of apoptotic and inflammatory complexes through homotypic protein-protein interactions [13]. Proteins with PYDs play important roles in the regulation of caspase-1 and thus modulate production of interleukin-1 (IL-1). In this regard, pyrin is thought to interact with another member of the superfamily, apoptosis-associated speck-like protein with a caspase recruitment domain (ASC). Recent work also suggests that pyrin may itself be a substrate for cleavage by caspase- 1 and that pyrin variants may serve as a more efficient substrate than the wild-type protein [14]. Another postulated mechanism by which variant pyrin could promote inflammation is translocation of the resulting $\mathrm{N}$-terminal PYD cleavage fragments to the nucleus, where they could potentiate activation of nuclear factor-kappa-B (NF-кB) [15].

\section{Clinical features}

FMF is the most common in Middle Eastern populations but occurs worldwide [16]. The prevalence of FMF is estimated to be $1 / 250$ to $1 / 500$ among Sephardic Jews and 1/1,000 in the Turkish population. Carrier frequency exceeds 1 in 4 in some eastern Mediterranean populations, prompting speculation that the FMF trait may have conferred survival benefit, possibly through enhanced resistance to microbial infection mediated via an upregulated innate immune response $[17,18]$. Males and females are affected equally and the disease usually presents in childhood.
Attacks of FMF occur irregularly and apparently spontaneously although some may be precipitated by minor physical or emotional stress, the menstrual cycle, or diet. Attacks evolve rapidly and symptoms resolve within 72 hours. Fever with serositis are the cardinal features, and these can vary from mild to incapacitating. Peritonitis that can mimic an acute surgical abdomen occurs in $85 \%$ of cases, and indeed $40 \%$ of patients will undergo exploratory surgery before FMF is diagnosed. Pleuritic chest pain occurs in $40 \%$ of patients, characteristically unilaterally, either alone or with peritonitis. Headache with features of meningism has been reported in children in particular, but the nervous system is not usually involved. Orchitis occurs in less than $5 \%$ of patients, most commonly in early childhood, and can be confused with testicular torsion. Joint involvement usually affects the lower limbs: arthralgia is common in acute attacks and usually subsides within a couple of days, but a chronic destructive arthritis can rarely occur. A characteristic erysipelas-like rash occurs in $20 \%$ of patients, usually around the ankles (Figure 1). A degree of myalgia can occur during acute attacks, but up to a fifth of patients complain of persistent muscle pain on exertion, usually affecting the calves. Protracted febrile myalgia is rare and is characterised by severe pain in the lower limbs or abdominal musculature which may persist for weeks and can be accompanied by a vasculitic rash; it usually responds to corticosteroids therapy.

Acute attacks are accompanied by a neutrophilic leukocytosis, raised erythrocyte sedimentation rate, and a dramatic acute-phase response. Investigations may be required to exclude other diagnoses but imaging by x-ray, ultrasound, or echocardiography during attacks is usually unrewarding.

Diagnosis is supported by DNA analysis but essentially remains clinical and centres on the history of recurrent selflimiting idiopathic attacks of fever and serositis that can be prevented by prophylatic colchicine treatment. Genetic results must be interpreted cautiously given that certain individuals with paired pathogenic MEFV mutations never develop FMF and that others with heterozygous carrier status can do so. Furthermore, most diagnostic laboratories offer only limited analysis of the large 10-exon MEFV gene.

\section{Treatment}

Supportive measures, including analgesia, are often required during acute attacks, but the mainstay of management is long-term prophylactic treatment with low-dose colchicine. This was discovered serendipitously in 1972 by Goldfinger [19] and has entirely transformed the outlook of this previously disabling disease. Continuous treatment with colchicine at a dose of 1 to $2 \mathrm{mg}$ daily in adults prevents or substantially reduces symptoms of FMF in at least $95 \%$ of cases and almost completely eliminates the risk of AA amyloidosis (see below). The mechanism of action of colchicine remains incompletely understood, but colchicine binds to tubulin and evidently modulates neutrophil adhesion, 


\section{Figure 1}

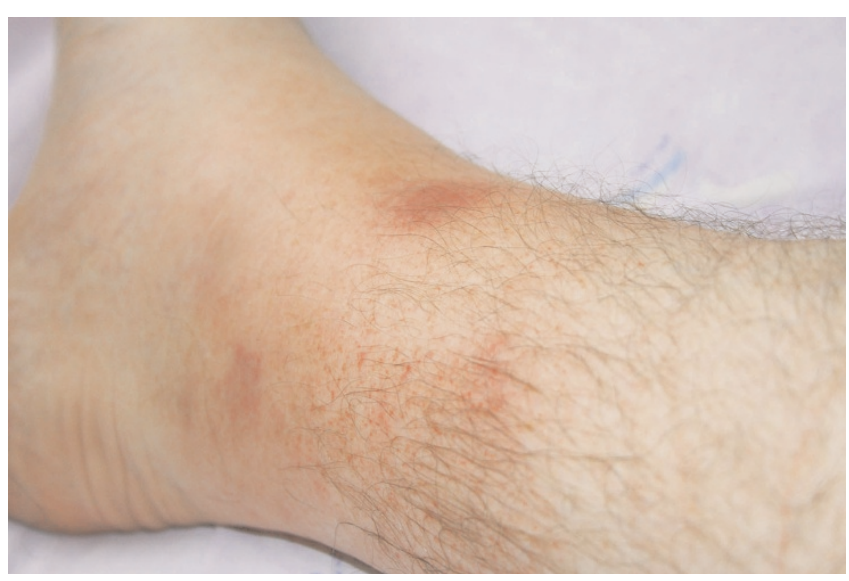

Erysipelas-like erythema around the ankle, the characteristic painful rash seen in attacks of familial Mediterranean fever.

mobility, and cytokine release in a presumably rather specific manner in patients with defective pyrin variants $[20,21]$.

Long-term colchicine is advisable in every patient with FMF and mandatory in those who already have AA amyloidosis. Although colchicine is very toxic in acute overdose, the low daily doses required for treatment of FMF are generally very well tolerated. Diarrhoea is the most common side effect and usually can be avoided by gradual introduction of the drug. Despite theoretical concerns, there is no evidence that colchicine causes infertility or birth defects and it can be taken safely by nursing mothers [22]. Colchicine is a purely prophylactic treatment in FMF, and introduction or dose escalation during an acute FMF attack is not generally effective.

Genuine resistance to colchicine is probably very rare, although issues of compliance are surprisingly common. Anecdotal reports of benefit from treatment with etanercept or anakinra in 'refractory' patients are beginning to emerge [23,24].

\section{Tumour necrosis factor receptor-associated periodic syndrome}

TRAPS is the second most common inherited fever syndrome, although with an estimated prevalence of about 1 per million in the UK, it is very rare.

\section{Genetics and pathophysiology}

TRAPS is an autosomal dominant disease associated with mutations in the gene for TNF receptor superfamily $1 \mathrm{~A}$ (TNFRSF1A), a 10-exon gene located on chromosome $12 \mathrm{p} 13$ [25]. TNF is a key mediator of inflammation with pleiotropic actions, including pyrexia, cachexia, leukocyte activation, induction of cytokine secretion, expression of adhesion molecules, and resistance to intracellular pathogens. TNF receptor 1 (TNFR1) is a member of the death domain superfamily and comprises an extracellular motif containing four cysteine-rich domains, a transmembrane domain, and an intracellular death domain. Binding of soluble circulating TNF causes trimerization of the receptor and activation of NF- $\kappa B$, with downstream induction of inflammation and inhibition of apoptosis via production of cellular caspase-8-like inhibitory protein (cFLIP). Events following endocytosis of the activated TNFR1 complex result in apoptosis. The mechanism(s) by which heterozygous TRFRSF1A mutations cause TRAPS remain unclear and may well differ between mutations. Most TRAPS-associated mutations lie within exons 2 to 4 , of which about half are missense substitutions affecting highly conserved cysteine residues that disrupt structurally important cysteine-cysteine disulphide bonds in the extracellular domain. Under normal circumstances, TNF signalling is terminated by metalloproteinase-dependent cleavage of a proximal region of the extracellular domain, which releases soluble TNFR1 that competitively inhibits binding of circulating TNF to cell surface receptors. Whilst cleavage of certain TNFR1 variants is impaired producing a 'shedding defect', this is not the case with other TRAPS-causing mutations, which must exert their pathogenic effect by different means. It is thought that mutant misfolded receptors may give rise to enhanced or prolonged signalling, possibly through retention within the endoplasmic reticulum [26-29]. Despite initial hopes to the contrary, the mechanisms and downstream effects by which TNFR1 mutations result in TRAPS remain far from clear.

\section{Clinical features}

The clinical entity now known as TRAPS was described in 1982 as familial Hibernian fever [30], reflecting the Irish/ Scottish ancestry of patients in early reports, but TRAPS has subsequently been reported in many ethnic groups, including Jews, Arabs, and Central Americans. Males and females are affected equally and presentation is usually before 4 years of age. Most mutations are associated with high penetrance, but two variants, P46L and R92Q, that can be associated with TRAPS are present in approximately $10 \%$ of healthy West Africans [31] and 1\% of healthy Caucasians, respectively.

Attacks in TRAPS are far less distinct than in FMF. Febrile episodes typically last 1 to 4 weeks and symptoms are nearly continuous in a third of patients. Approximately half of patients give no clear family history, many of whom have the $\mathrm{P} 46 \mathrm{~L}$ or $\mathrm{R} 92 \mathrm{Q}$ variants, which are also associated with milder disease and later onset [32]. The clinical picture varies: more than $95 \%$ of patients experience fever, and $80 \%$ have arthralgia or myalgia that typically follows a centripetal migratory path; abdominal pain occurs in 80\%; and skin manifestations, including erythematous rash (Figure 2), oedematous plaques (often overlying areas of mylagic pain), and discrete reticulate or serpiginous lesions, occur in $70 \%$ of patients. Other features include headache, pleuritic pain, lymphadenopathy, conjunctivitis, and periorbital oedema. There are also reports of central nervous system manifestations and imaging findings resembling multiple sclerosis 
[33]. Symptoms are almost universally accompanied by a marked acute-phase response. During quiescent periods, the plasma concentration of soluble TNFR1 may be abnormally low in patients with decreased receptor shedding. Genetic testing is central to diagnosis.

\section{Treatment}

Despite high initial hopes for response to anti-TNF biologics, treatment of TRAPS often remains disappointing. Acute attacks do respond to high-dose corticosteroids, and etanercept (but interestingly not infliximab) is useful in some patients, although response may gradually decline [34]. A recent report suggested that IL-1 blockade with anakinra can be very effective in some patients [35].

\section{The hyper IgD and periodic fever syndrome}

\section{Genetics and pathophysiology}

Hyper IgD and periodic fever syndrome (HIDS) is an autosomal recessive disease caused by mutations in the mevalonate kinase (MVK) gene on the long arm of chromosome 12 [36]. About 60 mutations have been described, spanning the 11-exon gene, the most common of which encode MVK variants V377I and I268T. MVK is the enzyme following HMG CoA (or 3-hydroxy-3-methylglutaryl-coenzyme A) reductase in the pathway involved in cholesterol, farnasyl, and isoprenoid biosynthesis. Most HIDS-causing MVK mutations are missense variants that reduce enzyme activity by $90 \%$ to $99 \%$ [37]. Other mutations resulting in near-complete absence of enzyme activity cause a much more severe inflammatory disease known as mevalonic aciduria (MVA), features of which include stillbirth, congenital malformations, severe psychomotor retardation, ataxia, myopathy, failure to thrive, and early death.

It is not yet known how MVK deficiency causes inflammation or increased $\operatorname{lgD}$ production, although reduction in prenylation due to failure of flux through the isoprenoid pathway currently seems more likely to be responsible than accumulation of the enzyme's substrate [38,39]. The relationship of the isoprenoid pathway to inflammation is of all the more interest given the anti-inflammatory properties of statin drugs that are widely used to inhibit cholesterol synthesis. Whilst various effects of statins on caspase-1 activation and IL-1 secretion have been postulated, a clinical study of simvastatin of six patients with HIDS suggested only minor benefit [40]; rather worryingly, two other children with MVA were reported to develop severe flares of inflammatory disease following statin treatment [41].

\section{Clinical features}

HIDS is extremely rare and is predominantly a Dutch disease, probably through a founder effect. It was described in The Netherlands in 1984 and the international registry in Nijmegen has data on just over 200 patients [42]. The carriage rate of MVK V337I is 1 in 350 in the Dutch population [43], but HIDS has been reported in many other

\section{Figure 2}

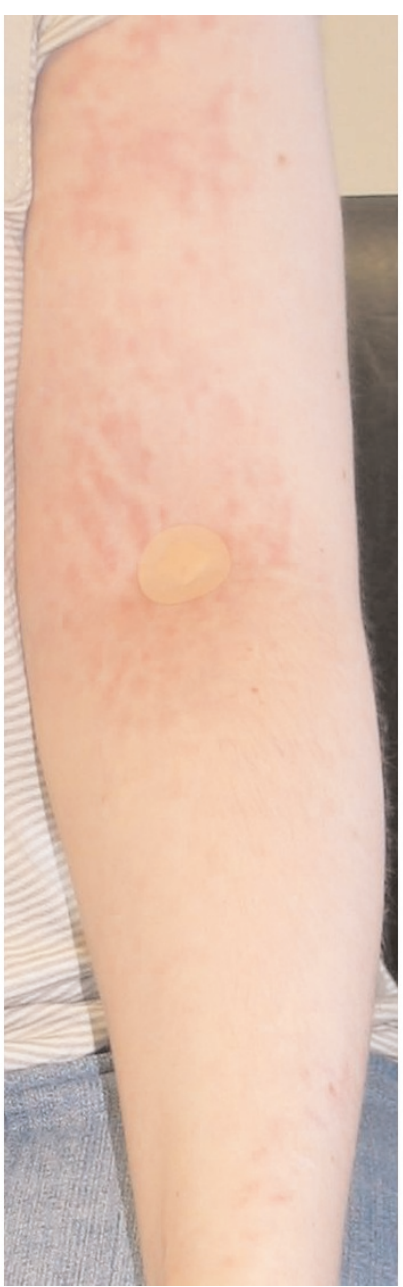

Erythematous rash complicating an acute attack in tumour necrosis factor receptor-associated periodic syndrome (TRAPS).

countries and other ethnic groups, including Arabs and Southeast Asians. The disease occurs equally in males and females and usually presents in the first year of life [44].

Attacks are irregular, typically lasting 4 to 7 days, and are characteristically provoked by vaccination, minor trauma, surgery, or stress, perhaps triggered by a reduction in MVK enzyme associated with increased body temperature [45]. Attacks of HIDS typically comprise fever, cervical lymphadenopathy, splenomegaly, and abdominal pain with vomiting and diarrhoea. Headache, arthralgia, large-joint arthritis, erythematous macules and papules, and aphthous ulcers are also common. HIDS typically ameliorates in adult life and older patients may remain well for years.

Diagnosis of HIDS is supported by a high serum $\lg D$ concentration, although this is not specific and is not always present [46]. More accessibly, serum $\lg A$ concentration is 
also elevated in $80 \%$ of patients. Attacks are accompanied by an acute-phase response, leukocytosis, and the transient presence of mevalonic acid in the urine. A mutation in both alleles of the MVK gene can be identified in most patients, including the MVK V337I variant in $50 \%$ to $80 \%$ of cases.

\section{Treatment}

Treatment is largely supportive, including nonsteroidal antiinflammatory drugs, although responses to etanercept $[47,48]$ and anakinra have lately been reported. A cautious therapeutic trial of statin therapy may be worthwhile.

\section{Cryopyrin-associated periodic syndrome}

CAPS comprises a much-overlapping spectrum of three hitherto separately described diseases, ranging from mild to severe, respectively: familial cold urticaria, now known as familial cold autoinflammatory syndrome (FCAS); MuckleWells syndrome (MWS); and chronic infantile neurological, cutaneous, and articular syndrome (CINCA), which is known in the US as neonatal onset multisystem inflammatory disease (NOMID).

\section{Genetics and pathophysiology}

CAPS is associated with various mutations in NLRP3/CIAS1 on chromosome 1q44, a gene that encodes the death domain protein known variously as NLRP3, NALP3, and cryopyrin [49]. Dominant inheritance is evident in about $75 \%$ of patients with FCAS and MWS, whereas CINCA, at the most severe end of the clinical spectrum, is usually due to de novo mutation. More than 60 , mostly missense, mutations have been reported and all but three of them are in exon 3 . The genotype-phenotype relationship can differ markedly between individuals, even within a family.

$N L R P 3$ is expressed in granulocytes, dendritic cells, B and T lymphocytes, epithelial cells of the oral and genital tracts, and chondrocytes. It encodes a protein that has a PYD, a nucleotide-binding site domain, and a leucine-rich repeat (LRR) motif. Signalling through a variety of danger signals, including intracellular pathogen associated molecular patterns (PAMP) and uric acid, results in the association of NLRP3 via its LRR with other members of the death domain superfamily to form a multimeric cytosolic protein complex, known collectively as the inflammasome [50,51]. This results in activation of caspase-1, which cleaves pro-IL-1 to produce active IL-1- $\beta$ and IL-1- $\alpha$; it also upregulates NF- $\kappa B$ expression and thereby increases $\mathrm{IL}-1$ gene expression. IL-1 is a major proinflammatory cytokine that mediates a multitude of local and systemic responses to infection and tissue injury and, as proved by the complete response of CAPS to IL-1 receptor blockade, is pivotal in causing the clinical features of this disease [52].

\section{Clinical features}

Most reported patients with CAPS have European ancestry but cases have been described from South Asia and elsewhere [53]. Onset of disease is usually in early infancy, often from birth, and there is no gender bias. FCAS is the most common in North America and was described in 1940 as recurrent episodes of cold-induced fever, arthralgia, conjunctivitis, and rash (Figure 3 ). MWS was described in 1962 [54] as a syndrome with often daily attacks of urticarial rash, conjunctivitis, arthralgia, and fever, complicated by progressive sensorineural deafness in $40 \%$ of patients, and a high risk of AA amyloidosis. CINCA is a sporadic severe inflammatory disorder that presents in the neonatal period with multisystem involvement including the skin, skeletal system, and central nervous system [55]. Bony overgrowth and premature ossification may occur particularly in the skull and knees (Figure 4); chronic aseptic meningitis results in developmental retardation; and blindness due to optic atrophy and deafness are also common. The relationship between these three overlapping syndromes, essentially encompassing a spectrum of severity, was recognised in only the past few years after their common genetic aetiology was discovered.

Clinical disease is accompanied by an acute-phase response and often leukocytosis and thrombocytosis and anaemia of chronic disease. Sensorineural hearing loss should be sought with audiometry, and characteristic bony abnormalities may be evident radiologically. Fundoscopy and brain imaging may show features consistent with elevated intracranial pressure. A mutation in NLRP3 can be identified in almost all patients with clinical FCAS or MWS, although mutations are found in only about $50 \%$ of children with classic CINCA; it is possible that 'mutation-negative' cases of FCAS and MWS may also exist but are simply not being recognised.

\section{Treatment}

Daily injections of anakinra (recombinant IL-1 receptor antagonist) produce rapid and complete clinical and serological remission in CAPS [52]. It is hoped that early anti-IL-1 therapy may prevent developmental abnormalities in children with disease toward the severe end of the spectrum [56]. Various new longer acting IL- 1 inhibitors are also proving to be very effective [57] and early safety and efficacy data look encouraging [58].

\section{Pyogenic sterile arthritis, pyoderma gangrenosum, and acne (PAPA) syndrome}

This exceptionally rare autosomal dominant disease is caused by mutations in the proline serine threonine phosphataseinteracting protein-1 (PTSTPIP) gene encoding a protein also known as CD2-binding protein-1 (CB2BP1) [59]. Stimulated macrophages isolated from patients demonstrate increased $\mathrm{IL}-1 \beta$ release, suggesting that mutations result in increased activation of caspase-1. The underlying pathogenesis remains poorly understood, although there is evidence that CD2BP1, which interacts with actin and is an important component of cytoskeletal organisation, interacts with pyrin [60]. This interaction is significantly increased by tyrosine phosphory- 


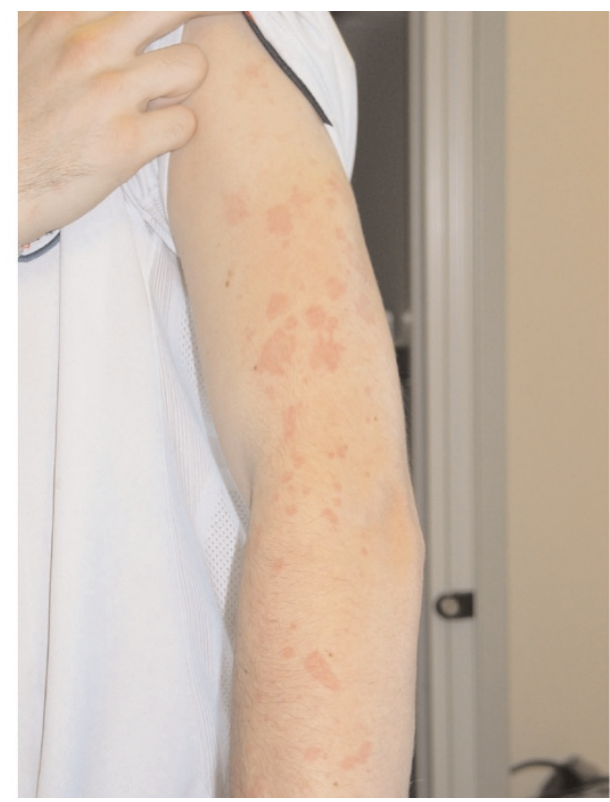

Characteristic urticarial lesions that develop almost every afternoon in this patient with cryopyrin-associated periodic syndrome (CAPS) accompanied by fever, generalised myalgia, and conjunctivitis.

lation of native CD2BP1. Disease-associated mutations have also been shown to potentiate the pyrin-CD2BP1 interaction. There is some evidence that this may result in unmasking of pyrin's PYD domain and thus a possible mechanism by which mutations could result in caspase-1 activation [61]. PAPA is characterised clinically by severe acne and recurrent pustular sterile arthritis that typically occurs after minor trauma. Early reports suggest that therapy with anakinra may be effective.

\section{Blau syndrome or early-onset sarcoidosis}

This sarcoid-like syndrome was described in 1985 as an autosomal dominant syndrome of granulomatous infiltration of the joints causing camptodactyly, skin, and sometimes viscera associated with uveitis [62]. Another syndrome, early-onset sarcoidosis, is probably the same disease and both have been shown to be associated with missense mutations in NOD2/ CARD15. This is another member of the death domain superfamily [63] and is thought to serve as an intracellular receptor for PAMPs leading to NF- $\kappa$ B activation. NOD2 mutations have also been implicated in familial Crohn disease, another granulomatous disease. Treatment is with corticosteroids.

\section{Acquired autoinflammatory conditions Schnitzler syndrome}

Schnitzler syndrome is a disorder of unknown pathogenesis characterised by relapsing urticarial rashes, periodic fevers, arthralgias/arthritis, lymphadenopathy, and IgM paraproteinaemia, which can be of a very low level. Fewer than 100 patients have been reported. Onset is in adulthood, reflecting susceptibility with increasing age to paraproteinaemia. Long-

\section{Figure 4}

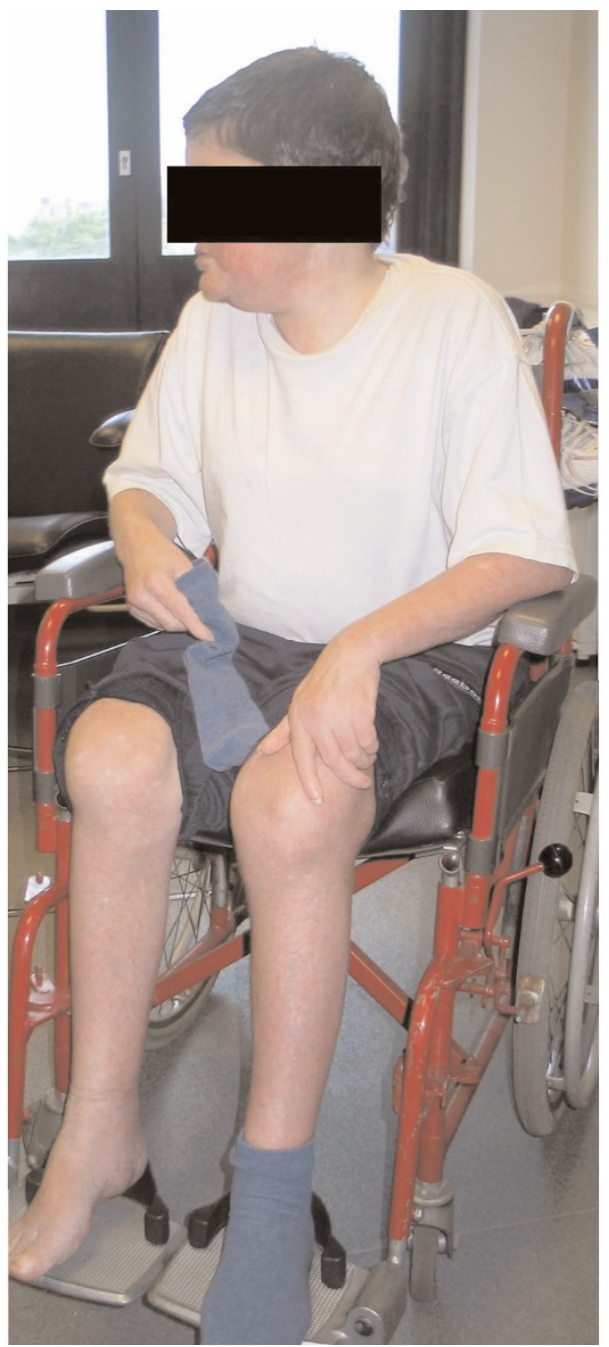

Severe cryopyrin-associated periodic syndrome (CAPS), toward the chronic infantile neurological, cutaneous, and articular syndrome (CINCA) end of the spectrum, is frequently associated with arthropathy as shown here. The knees are enlarged with deformed femora without synovitis. Short stature and finger clubbing are also well-recognised features of the syndrome.

term outcomes appear good, with 15-year survival exceeding $90 \%$, although overt lymphoproliferative disease evolves in more than $15 \%$ of patients. Chemotherapy directed toward the underlying clonal B-cell disorder is effective in some but not all patients, possibly due to the low proportion in whom complete suppression of the IgM paraproteinaemia can be achieved. A pivotal role of $\mathrm{IL}-1$ in the pathogenesis of this acquired disorder has lately been suggested by remarkable therapeutic efficacy of anakinra in a number of patients [64].

\section{Gout and pseudogout}

A place for these acute inflammatory arthritides in the umbrella of autoinflammatory disorders has recently been 
suggested by observations that monosodium urate (MSU) and/or calcium pyrophosphate dihydrate (CPPD) crystals can activate the NLRP3 inflammasome, resulting in the production of active IL1- $\beta$ and IL-18 [65]. Macrophages from mice with knockouts of a variety of inflammasome components produce significantly less IL-1 $\beta$ compared with wild-type animals following challenge with MSU or CPPD crystals. Involvement of IL-1 $\beta$ in crystal arthritis has recently been confirmed clinically in an open-label study of anakinra in 10 patients with acute gout [66].

\section{Long-term outcomes}

Although CINCA/NOMID can be sufficiently severe to cause death within the first few decades, life expectancy among many patients with autoinflammatory disorders is typically near normal and is expected to be excellent in those for whom there is now effective therapy. The most serious and life-threatening complication of these diseases generally is AA amyloidosis.

\section{AA amyloidosis}

Reactive systemic (AA) amyloidosis is an often fatal disorder, predominantly affecting the kidneys, which occurs in a small proportion of patients with one of a wide range of chronic inflammatory diseases [67]. AA amyloid fibrils are derived from the circulating acute-phase reactant serum amyloid A protein (SAA), and their accumulation in tissues throughout the body progressively damages the structure and function of vital organs. SAA is synthesised by the liver under transcriptional regulation of IL-1, interleukin 6 (IL-6) and TNF- $\alpha$, and its plasma concentration, which in health is less than $3 \mathrm{mg} / \mathrm{l}$, may rise a thousand fold in the presence of inflammation [68]. Whilst the lifetime incidence of AA amyloidosis is about $1 \%$ to $5 \%$ in patients with chronic inflammatory diseases generally, it is much more common among patients with inherited periodic fever syndromes, although the factors that determine susceptibility to its development, other than the presence of an acute-phase response for a long period, are not known. The median duration of inflammatory disease in patients who develop amyloidosis is about 20 years, and the life-long nature of inherited periodic fever syndromes is presumably a factor in the high prevalence of amyloid in these diseases; another factor may be the unusually high plasma concentrations of SAA that typically occur in inherited periodic fever syndromes. Up to $60 \%$ of patients with FMF died of renal failure due to $A A$ amyloidosis before prophylactic colchicine was widely prescribed, and even recently it was reported in $13 \%$ of a large Turkish series. The incidence of AA amyloidosis in TRAPS and CAPS is approximately $25 \%$ but is less than $5 \%$ in HIDS, perhaps because the disease often ameliorates spontaneously in early adulthood. The natural history of untreated AA amyloidosis is of renal failure and early death, but this can be prevented by treatment of the underlying inflammatory disorder that substantially suppresses SAA production.

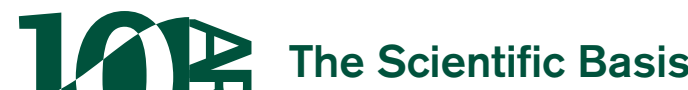 of Rheumatology: A Decade of Progress}

This article is part of a special collection of reviews, The Scientific Basis of Rheumatology: A Decade of Progress, published to mark Arthritis Research \& Therapy's 10th anniversary.

Other articles in this series can be found at: http://arthritis-research.com/sbr

\section{Conclusions}

Recent progress in elucidating the pathogenesis of many autoinflammatory diseases has led to major advances in their treatment, most remarkably the introduction of IL- 1 inhibition in CAPS. The clinical significance of low-penetrance mutations/polymorphisms in the inherited period fever syndrome genes remains unclear, although there is early evidence that they may potentiate inflammation more generally $[69,70]$. The multitude of studies currently in progress, both in rare hereditary autoinflammatory diseases and in more common acquired ones (including Crohn disease, systemic onset juvenile arthritis, and Behçet syndrome), are expected to shed important further light on aspects of the innate immune system and inflammation generally over the next few years.

\section{Competing interests}

The authors declare that they have no competing interests.

\section{Acknowledgements}

Written consent for publication of their photographs was obtained from all patients featured in this article.

\section{References}

1. Heller $\mathrm{H}$, Sohar $\mathrm{E}$, Sherf L: Familial Mediterranean fever. AMA Arch Intern Med 1958, 102:50-71.

2. Consortium TFF: A candidate gene for familial Mediterranean fever. Nat Genet 1997, 17:25-31.

3. Consortium TIF: Ancient missense mutations in a new member of the RoRet gene family are likely to cause familial Mediterranean fever. Cell 1997, 90:797-807.

4. Centola M, Wood G, Frucht DM, Galon J, Aringer M, Farrell C, Kingma DW, Horwitz ME, Mansfield E, Holland SM, O'Shea JJ, Rosenberg HF, Malech HL, Kastner DL: The gene for familial Mediterranean fever, MEFV, is expressed in early leukocyte development and is regulated in response to inflammatory mediators. Blood 2000, 95:3223-3231.

5. Infevers homepage [http://fmf.igh.cnrs.fr/ISSAID/infevers].

6. Lachmann HJ, Sengül B, Yavuzsen TU, Booth DR, Booth SE, Bybee A, Gallimore JR, Soytürk M, Akar S, Tunca M, Hawkins PN: Clinical and subclinical inflammation in patients with familial Mediterranean fever and in heterozygous carriers of MEFV mutations. Rheumatology (Oxford) 2006, 45:746-750.

7. Booth DR, Gillmore JD, Lachmann HJ, Booth SE, Bybee A, Soytürk M, Akar S, Pepys MB, Tunca M, Hawkins PN: The genetic basis of autosomal dominant familial Mediterranean fever. QJM 2000, 93:217-221. 
8. Cañete JD, Arostegui Jl, Queiró R, Gratacós J, Hernández MV, Larrosa M, Alperí M, Moll C, Rius J, Sanmartí R, Yagüe J: An unexpectedly high frequency of MEFV mutations in patients with anti-citrullinated protein antibody-negative palindromic rheumatism. Arthritis Rheum 2007, 56:2784-2788.

9. Kalyoncu M, Acar BC, Cakar N, Bakkaloglu A, Ozturk S, Dereli E, Tunca M, Kasapcopur O, Yalcinkaya F, Ozen S: Are carriers for MEFV mutations "healthy"? Clin Exp Rheumatol 2006, 24: S120-122.

10. Hall MW, Gavrilin MA, Knatz NL, Duncan MD, Fernandez SA, Wewers MD: Monocyte mRNA phenotype and adverse outcomes from pediatric multiple organ dysfunction syndrome. Pediatr Res 2007, 62:597-603.

11. Tidow N, Chen X, Müller C, Kawano S, Gombart AF, FischelGhodsian N, Koeffler HP: Hematopoietic-specific expression of MEFV, the gene mutated in familial Mediterranean fever, and subcellular localization of its corresponding protein, pyrin. Blood 2000, 95:1451-1455.

12. Martinon F, Hofmann K, Tschopp J: The pyrin domain: a possible member of the death domain-fold family implicated in apoptosis and inflammation. Curr Bio/ 2001, 10:R118-R120.

13. Park HH, Lo YC, Lin SC, Wang L, Yang JK, Wu H: The death domain superfamily in intracellular signaling of apoptosis and inflammation. Annu Rev Immuno/ 2007, 25:561-586.

14. Chae JJ, Wood G, Masters SL, Richard K, Park G, Smith BJ, Kastner DL: The B30.2 domain of pyrin, the familial Mediterranean fever protein, interacts directly with caspase-1 to modulate IL-1 beta production. Proc Natl Acad Sci U S A 2006, 103: 9982-9987.

15. Chae JJ, Wood G, Richard K, Jaffe H, Colburn NT, Masters SL, Gumucio DL, Shoham NG, Kastner DL: The familial Mediterranean fever protein, pyrin, is cleaved by caspase-1 and activates NF-kappaB through its $\mathrm{N}$-terminal fragment. Blood 2008, 112:1794-1803.

16. Mikula M, Buller A, Sun W, Strom CM: Prevalence of known mutations in the familial Mediterranean fever gene (MEFV) in various carrier screening populations. Genet Med 2008, 10: 349-352.

17. Ross JJ: Goats, germs, and fever: are the pyrin mutations responsible for familial Mediterranean fever protective against Brucellosis? Med Hypotheses 2007, 68:499-501.

18. Schaner P, Richards N, Wadhwa A, Aksentijevich I, Kastner D, Tucker P, Gumucio D: Episodic evolution of pyrin in primates: human mutations recapitulate ancestral amino acid states. Nat Genet 2001, 27:318-321.

19. Goldfinger SE: Colchicine for familial Mediterranean fever. $N$ Engl J Med 1972, 287:1302.

20. Rigante D, La Torraca I, Avallone L, Pugliese AL, Gaspari S, Stabile A: The pharmacologic basis of treatment with colchicine in children with familial Mediterranean fever. Eur Rev Med Pharmacol Sci 2006, 10:173-178.

21. Chia EW, Grainger R, Harper JL: Colchicine suppresses neutrophil superoxide production in a murine model of gouty arthritis: a rationale for use of low-dose colchicine. $\mathrm{Br} J \mathrm{Phar}^{-}$ macol 2008, 153:1288-1295.

22. Ben-Chetrit $E$, Levy $M$ : Reproductive system in familial Mediterranean fever: an overview. Ann Rheum Dis 2003, 62:916-919.

23. Mor A, Pillinger $\mathrm{MH}$, Kishimoto $\mathrm{M}$, Abeles $\mathrm{AM}$, Livneh $\mathrm{A}$ : Familial Mediterranean fever successfully treated with etanercept. J Clin Rheumatol 2007, 13:38-40.

24. Roldan R, Ruiz AM, Miranda MD, Collantes $E$. Anakinra: new therapeutic approach in children with Familial Mediterranean Fever resistant to colchicine. Joint Bone Spine 2008, 75:504505.

25. McDermott MF, Aksentijevich I, Galon J, McDermott EM, Ogunkolade BW, Centola M, Mansfield E, Gadina M, Karenko L, Pettersson T, McCarthy J, Frucht DM, Aringer M, Torosyan Y, Teppo AM Wilson M, Karaarslan HM, Wan Y, Todd I, Wood G, Schlimgen R, Kumarajeewa TR, Cooper SM, Vella JP, Amos Cl, Mulley J, Quane KA, Molloy MG, Ranki A, Powell RJ, et al.: Germline mutations in the extracellular domains of the $55 \mathrm{kDa}$ TNF receptor, TNFR1, define a family of dominantly inherited autoinflammatory syndromes. Cell 1999, 97:133-144.

26. D'Osualdo A, Ferlito F, Prigione I, Obici L, Meini A, Zulian F, Pontillo A, Corona F, Barcellona R, Di Duca M, Santamaria G, Traverso F, Picco P, Baldi M, Plebani A, Ravazzolo R, Ceccherini I, Martini A, Gattorno M: Neutrophils from patients with
TNFRSF1A mutations display resistance to tumor necrosis factor-induced apoptosis: pathogenetic and clinical implications. Arthritis Rheum 2006, 54:998-1008.

27. Rebelo SL, Bainbridge SE, Amel-Kashipaz MR, Radford PM, Powell RJ, Todd I, Tighe PJ: Modeling of tumor necrosis factor receptor superfamily $1 \mathrm{~A}$ mutants associated with tumor necrosis factor receptor-associated periodic syndrome indicates misfolding consistent with abnormal function. Arthritis Rheum 2006, 54:2674-2687.

28. Todd I, Radford PM, Daffa N, Bainbridge SE, Powell RJ, Tighe PJ: Mutant tumor necrosis factor receptor associated with tumor necrosis factor receptor-associated periodic syndrome is altered antigenically and is retained within patients' leukocytes. Arthritis Rheum 2007, 56:2765-2773.

29. Nedjai B, Hitman GA, Yousaf N, Chernajovsky Y, StjernbergSalmela S, Pettersson T, Ranki A, Hawkins PN, Arkwright PD, McDermott MF, Turner MD: Abnormal tumor necrosis factor receptor I cell surface expression and NF-KB activation in tumor necrosis factor receptor-associated periodic syndrome. Arthritis Rheum 2008, 58:273-283.

30. Williamson LM, Hull D, Mehta R, Reeves WG, Robinson BH, Toghill PJ: Familial Hibernian fever. QJM 1982, 51:469-480.

31. Tchernitchko D, Chiminqgi M, Galactéros F, Préhu C, Segbena Y, Coulibaly H, Rebaya N, Loric S: Unexpected high frequency of P46L TNFRSF1A allele in sub-Saharan West African populations. Eur J Hum Genet 2005, 13:513-515.

32. Ravet N, Rouaghe S, Dodé C, Bienvenu J, Stirnemann J, Lévy P, Delpech M, Grateau G: Clinical significance of P46L and R920 substitutions in the tumour necrosis factor superfamily $1 \mathrm{~A}$ gene. Ann Rheum Dis 2006, 65:1158-1162.

33. Hoffmann LA, Lohse $\mathrm{P}$, Konig FB, Feneberg W, Hohlfeld R, Kumpfel T: TNFRSF1A R92Q mutation in association with a multiple sclerosis-like demyelinating syndrome. Neurology 2008, 70:1155-1156.

34. Nowlan ML, Drewe E, Bulsara H, Esposito N, Robins RA, Tighe PJ, Powell RJ, Todd I: Systemic cytokine levels and the effects of etanercept in TNF receptor-associated periodic syndrome (TRAPS) involving a C33Y mutation in TNFRSF1A. Rheumato/ogy (Oxford) 2006, 45:31-37.

35. Gattorno M, Pelagatti MA, Meini A, Obici L, Barcellona R, Federici S, Buoncompagni A, Plebani A, Merlini G, Martini A: Persistent efficacy of anakinra in patients with tumor necrosis factor receptor-associated periodic syndrome. Arthritis Rheum 2008, 58:1516-1520.

36. van der Meer JW, Vossen JM, Radl J, van Nieuwkoop JA, Meyer CJ, Lobatto S, van Furth R: Hyperimmunoglobulinaemia D and periodic fever: a new syndrome. Lancet 1984, 1:1087-1090.

37. Cuisset L, Drenth JP, Simon A, Vincent MF, van der Velde Visser S, van der Meer JW, Grateau G, Delpech M; International HyperIgD Study Group: Molecular analysis of MVK mutations and enzymatic activity in hyper-IgD and periodic fever syndrome. Eur J Hum Genet 2001, 9:260-266.

38. Houten SM, Frenkel J, Waterham HR: Isoprenoid biosynthesis in hereditary periodic fever syndromes and inflammation. Cell Mol Life Sci 2003, 60:1118-1134.

39. Schneiders MS, Houten SM, Turkenburg M, Wanders RJ, Waterham HR: Manipulation of isoprenoid biosynthesis as a possible therapeutic option in mevalonate kinase deficiency. Arthritis Rheum 2006, 54:2306-2313.

40. Simon A, Drewe E, van der Meer JW, Powell RJ, Kelley RI, Stalenhoef AF, Drenth JP: Simvastatin treatment for inflammatory attacks of the hyperimmunoglobulinemia $D$ and periodic fever syndrome. Clin Pharmacol Ther 2004, 75:476-483.

41. Hoffmann GF, Charpentier C, Mayatepek E, Mancini J, Leichsenring M, Gibson KM, Divry P, Hrebicek M, Lehnert W, Sartor K, Trefz FK, Rating D, Bremer HJ, Nyhan WL: Clinical and biochemical phenotype in 11 patients with mevalonic aciduria. Pediatrics 1993, 91:915-921.

42. Hyper-IgD and periodic fever syndrome (HIDS) homepage [http://www.hids.net].

43. Houten SM, van Woerden CS, Wijburg FA, Wanders RJ, Waterham HR: Carrier frequency of the V377I (1129G>A) MVK mutation, associated with Hyper-IgD and periodic fever syndrome, in the Netherlands. Eur J Hum Genet 2003, 11:196200.

44. Drenth JP, Haagsma CJ, van der Meer JW: Hyperimmunoglobulinemia D and periodic fever syndrome. The clinical spectrum 
in a series of 50 patients. International Hyper-IgD Study Group. Medicine (Baltimore) 1994, 73:133-144.

45. Houten SM, Frenkel J, Rijkers GT, Wanders RJ, Kuis W, Waterham HR: Temperature dependence of mutant mevalonate kinase activity as a pathogenic factor in hyper-lgD and periodic fever syndrome. Hum Mol Genet 2002, 11:3115-3124.

46. Ammouri W, Cuisset L, Rouaghe S, Rolland MO, Delpech M, Grateau G, Ravet N: Diagnostic value of serum immunoglobulinaemia D level in patients with a clinical suspicion of hyper IgD syndrome. Rheumatology (Oxford) 2007, 46:1597-1600.

47. Takada K, Aksentijevich I, Mahadevan V, Dean JA, Kelley RI, Kastner DL: Favorable preliminary experience with etanercept in two patients with the hyperimmunoglobulinemia $D$ and periodic fever syndrome. Arthritis Rheum 2003, 48:2645-2651.

48. Lachmann HJ, Goodman HJ, Andrews PA, Gallagher H, Marsh J, Breuer S, Rowczenio DM, Bybee A, Hawkins PN: AA amyloidosis complicating hyperimmunoglobulinemia $D$ with periodic fever syndrome: a report of two cases. Arthritis Rheum 2006, 54:2010-2014

49. Hoffman HM, Wright FA, Broide DH, Wanderer AA, Kolodner RD: Identification of a locus on chromosome 1q44 for familial cold urticaria. Am J Hum Genet 2000, 66:1693-1698.

50. Tschopp J, Martinon F, Burns K: NALPs: a novel protein family involved in inflammation. Nat Rev Mol Cell Biol 2003, 4:95104.

51. Martinon F, Agostini L, Meylan E, Tschopp J: Identification of bacterial muramyl dipeptide as activator of the NALP3/cryopyrin inflammasome. Curr Biol 2004, 14:1929-1934.

52. Hawkins PN, Lachmann HJ, McDermott MF: Interleukin-1-receptor antagonist in the Muckle-Wells syndrome. $N$ Engl J Med 2003, 348:2583-2584.

53. Leslie KS, Lachmann HJ, Bruning E, McGrath JA, Bybee A, Gallimore JR, Roberts PF, Woo P, Grattan CE, Hawkins PN: Phenotype, genotype, and sustained response to anakinra in 22 patients with autoinflammatory disease associated with CIAS-1/NALP3 mutations. Arch Dermatol 2006, 142:15911597.

54. Muckle TJ, Wells MV: Urticaria, deafness and amyloidosis: a new heredo-familial syndrome. QJM 1962, 31:235-248.

55. Prieur AM, Griscelli C, Lampert F, Truckenbrodt H, Guggenheim MA, Lovell DJ, Pelkonnen P, Chevrant-Breton J, Ansell BM: A chronic, infantile, neurological, cutaneous and articular (CINCA) syndrome. A specific entity analysed in $\mathbf{3 0}$ patients. Scand J Rheumatol Suppl 1987, 66:57-68.

56. Goldbach-Mansky R, Dailey NJ, Canna SW, Gelabert A, Jones J, Rubin BI, Kim HJ, Brewer C, Zalewski C, Wiggs E, Hill S, Turner ML, Karp BI, Aksentijevich I, Pucino F, Penzak SR, Haverkamp $\mathrm{MH}$, Stein L, Adams BS, Moore TL, Fuhlbrigge RC, Shaham B, Jarvis JN, O'Neil K, Vehe RK, Beitz LO, Gardner G, Hannan WP, Warren RW, Horn W, et al:: Neonatal-onset multisystem inflammatory disease responsive to interleukin-1b inhibition. N Engl J Med 2006, 355:581-592.

57. Hoffman HM, Throne ML, Amar NJ, Sebai M, Kivitz AJ, Kavanaugh A, Weinstein SP, Belomestnov P, Yancopoulos GD, Stahl N, Mellis SJ: Efficacy and safety of rilonacept (interleukin-1 trap) in patients with cryopyrin-associated periodic syndromes: results from two sequential placebo-controlled studies. Arthritis Rheum 2008, 58:2443-2452.

58. Goldbach-Mansky R, Shroff SD, Wilson M, Snyder C, Plehn S, Barham B, Pham TH, Pucino F, Wesley RA, Papadopoulos JH, Weinstein SP, Mellis SJ, Kastner DL: A pilot study to evaluate the safety and efficacy of the long-acting interleukin-1 inhibitor rilonacept (interleukin-1 Trap) in patients with familial cold autoinflammatory syndrome. Arthritis Rheum 2008, 58: 2432-2442.

59. Wise CA, Gillum JD, Seidman CE, Lindor NM, Veile R, Bashiardes $\mathrm{S}$, Lovett $\mathrm{M}$ : Mutations in CD2BP1 disrupt binding to PTP PEST and are responsible for PAPA syndrome, an autoinflammatory disorder. Hum Mol Genet 2002, 11:961-969.

60. Shoham NG, Centola M, Mansfield E, Hull KM, Wood G, Wise CA, Kastner DL: Pyrin binds the PSTPIP1/CD2BP1 protein, defining familial Mediterranean fever and PAPA syndrome as disorders in the same pathway. Proc Natl Acad Sci U S A 2003, 100:13501-13506.

61. Yu JW, Fernandes-Alnemri T, Datta P, Wu J, Juliana C, Solorzano L, McCormick M, Zhang Z, Alnemri ES: Pyrin activates the ASC pyroptosome in response to engagement by autoinflamma- tory PSTPIP1 mutants. Mo/ Cell 2007, 28:214-227.

62. Blau EB: Familial granulomatous arthritis, iritis, and rash. $J$ Pediatr 1985, 107:689-693.

63. Miceli-Richard C, Lesage S, Rybojad M, Prieur AM, ManouvrierHanu S, Häfner R, Chamaillard M, Zouali $H$, Thomas G, Hugot JP: CARD15 mutations in Blau syndrome. Nat Genet 2001, 29:1920.

64. de Koning HD, Bodar EJ, van der Meer JW, Simon A: Schnitzler syndrome: beyond the case reports: review and follow-up of 94 patients with an emphasis on prognosis and treatment. Semin Arthritis Rheum 2007, 37:137-148.

65. Martinon F, Petrilli V, Mayor A, Tardivel A, Tschopp J: Gout-associated uric acid crystals activate the NALP3 inflammasome. Nature 2006, 440:237-241.

66. So A, De Smedt T, Revaz S, Tschopp J: A pilot study of IL-1 inhibition by anakinra in acute gout. Arthritis Res Ther 2007, 9: R28.

67. Lachmann HJ, Goodman HJ, Gilbertson JA, Gallimore JR, Sabin CA, Gillmore JD, Hawkins PN: Natural history and outcome in systemic AA amyloidosis. N Engl J Med 2007, 356:2361-2371.

68. Ledue TB, Weiner DL, Sipe JD, Poulin SE, Collins MF, Rifai N: Analytical evaluation of particle-enhanced immunonephelometric assays for $\mathrm{C}$-reactive protein, serum amyloid $\mathrm{A}$ and mannose-binding protein in human serum. Ann Clin Biochem 1998, 35:745-753.

69. Aganna E, Hawkins PN, Ozen S, Pettersson T, Bybee A, McKee SA, Lachmann HJ, Karenko L, Ranki A, Bakkaloglu A, Besbas N, Topaloglu R, Hoffman HM, Hitman GA, Woo P, McDermott MF: Allelic variants in genes associated with hereditary periodic fever syndromes as susceptibility factors for reactive systemic AA amyloidosis. Genes Immun 2004, 5:289-293.

70. Aksentijevich I, Galon J, Soares M, Mansfield E, Hull K, Oh HH, Goldbach-Mansky R, Dean J, Athreya B, Reginato AJ, Henrickson M, Pons-Estel B, O'Shea JJ, Kastner DL: The tumor-necrosisfactor receptor-associated periodic syndrome: new mutations in TNFRSF1A, ancestral origins, genotype-phenotype studies, and evidence for further genetic heterogeneity of periodic fevers. Am J Hum Genet 2001, 69:301-314. 